\title{
BITE SIZE: 5 Minutes Writing Tips
}

Matteo Cavalleri ${ }^{1}$

${ }^{1}$ Affiliation not available

February 18, 2021

\begin{abstract}
When you want "Writing Tips For Your Research Articles" but you have only 5 minutes

Rich media available at https://speakerdeck.com/teowaits/bite-size-5-minutes-writing-tips 5 Min Writing Tips
\end{abstract}

How to write a great research paper

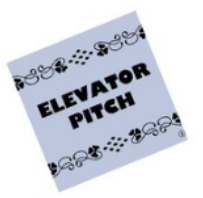

1. Have something to say

2. Say it

3. Stop as soon as you have said it.

46

WiLEY

Figure 1: 1.Have something to say 2. Say it 3. Stop as soon as you have said it 